\title{
The Early Emergence of Guilt-Motivated Prosocial Behavior
}

\author{
Amrisha Vaish \\ Max Planck Institute for Evolutionary Anthropology and \\ University of Virginia
}

\author{
Malinda Carpenter \\ Max Planck Institute for Evolutionary Anthropology and \\ University of St Andrews
}

\author{
Michael Tomasello \\ Max Planck Institute for Evolutionary Anthropology/Duke University
}

\begin{abstract}
Guilt serves vital prosocial functions: It motivates transgressors to make amends, thus restoring damaged relationships. Previous developmental research on guilt has not clearly distinguished it from sympathy for a victim or a tendency to repair damage in general. The authors tested 2- and 3-year-old children ( $N=62$ and 64 , respectively) in a $2 \times 2$ design, varying whether or not a mishap caused harm to someone and whether children themselves caused that mishap. Three-year-olds showed greatest reparative behavior when they had caused the mishap and it caused harm, thus showing a specific effect of guilt. Two-year-olds repaired more whenever harm was caused, no matter by whom, thus showing only an effect of sympathy. Guilt as a distinct motivator of prosocial behavior thus emerges by at least 3 years.
\end{abstract}

Guilt is the aversive emotion that follows the realization that one has harmed another person (Hoffman, 1982; Tangney \& Dearing, 2002). Like other self-conscious emotions, guilt is likely central to socialization and the adherence to social norms. Critically, guilt also motivates reparative and prosocial behaviors, thus playing a vital role in regulating social interactions. For instance, although guilt has no single facial expression, transgressors who feel guilty generally express remorse, for example, by stating that the harm was accidental, apologizing, and expressing the desire to repair (Fessler \& Haley, 2003; Keltner, 1995; Zahn-Waxler \& Kochanska, 1990). Moreover, the aversive feeling of guilt focuses the transgressor's attention on the harm done and motivates the transgressor to make amends (Hoffman, 1982; Keltner, 1995). Among adults, experiencing guilt after transgressing increases the help that transgressors provide to victims (e.g., Ketelaar \& Au, 2003; Regan, Williams, \& Sparling, 1972). Together, these behaviors restore the physical damage caused and also

Amrisha Vaish was supported by a Dilthey Fellowship from the Volkswagen Foundation and Fritz Thyssen Foundation. We thank all the daycare centers and children for their friendly cooperation; Eva Siegert, Elena Rossi, Christiane Markmann, Elvira Portner, and Kristina Schilke for assistance with testing and coding; Colleen Stephens for statistical support; and Tobias Grossmann and Robert Hepach for helpful discussions.

Correspondence concerning this article should be addressed to Amrisha Vaish, Department of Psychology, University of Virginia, 102 Gilmer Hall, Charlottesville, VA 22903. Electronic mail may be sent to vaish@virginia.edu. restore equity and foster social attachment, thereby repairing damaged relationships and sustaining cooperation (Baumeister, Stillwell, \& Heatherton, 1994; Frank, 1988; Keltner \& Anderson, 2000). Guilt thus serves vital prosocial functions.

Little is known, however, about the development of the prosocial functions of guilt. We do know that 4- to 5-year-old children are themselves appeased by others' guilt displays and are more prosocial toward remorseful than unremorseful transgressors (Smith, Chen, \& Harris, 2010; Smith \& Harris, 2012; Vaish, Carpenter, \& Tomasello, 2011; Wellman, Larkey, \& Somerville, 1979). What is less clear is when in development children themselves experience guilt and show the associated reparative and prosocial behaviors.

Most extant work on this topic has focused on children's responses following minor transgressions (e.g., accidentally breaking someone's favorite doll). This work suggests that by 2 years of age, children show signs of guilt such as accepting responsibility for their actions and attempting to repair the damage (Barrett, Zahn-Waxler, \& Cole, 1993; ZahnWaxler \& Kochanska, 1990; Zahn-Waxler \& RadkeYarrow, 1982). Moreover, these guilt-relevant responses are related to child characteristics such as

(C) 2016 The Authors

Child Development (C) 2016 Society for Research in Child Development, Inc. All rights reserved. 0009-3920/2016/8706-0011

DOI: $10.1111 /$ cdev. 12628 
temperament and to social factors such as parenting style and maternal depression (e.g., Kochanska, 1991; Kochanska, Casey, \& Fukumoto, 1995; Kochanska, Gross, Lin, \& Nichols, 2002; ZahnWaxler, Kochanska, Krupnick, \& McKnew, 1990). This work has been invaluable to our understanding of early social development. However, it remains unclear whether it has tapped into guilt specifically or rather into related but distinct processes. In particular, guilt is argued to be composed of two critical components: sympathy (feelings of concern) for a victim of harm and the awareness that one has caused that harm. Neither component is by itself sufficient; rather, it is the conjunction of the two that gives rise to guilt (Hoffman, 1976, 1982). Thus, to study the development and prosocial functions of guilt, it is essential to tease apart these different processes.

Prior work has been equivocal in this regard. For instance, (Zahn-Waxler \& Kochanska, 1990; ZahnWaxler \& Radke-Yarrow, 1982) observed 2-year-old children's responses to others' distress. In some cases, children had caused the distress, whereas in other cases, they were observers. Children comforted victims similarly in both cases, yet their prosocial behaviors were interpreted as evidence for guilt when children had caused the distress, but as sympathy when children were observers (Zahn-Waxler \& Kochanska, 1990; Zahn-Waxler \& Radke-Yarrow, 1982). However, it is possible that children were motivated by sympathy both as transgressors and as observers. Indeed, there is extensive evidence that as observers, children sympathize with and act prosocially toward those in need (e.g., Hepach, Vaish, \& Tomasello, 2012a, 2012b; Vaish, Carpenter, \& Tomasello, 2009; Zahn-Waxler, Radke-Yarrow, Wagner, \& Chapman, 1992). If young children are similarly prosocial after transgressing, it is difficult to conclude that this results from guilt rather than sympathy.

There are some hints that young children do behave differently when they are transgressors versus observers. For instance, 2- to 3-year-olds make more active efforts to understand harm they have witnessed than harm they have caused (ZahnWaxler \& Radke-Yarrow, 1982; Zahn-Waxler et al., 1992). It is possible, though, that children simply react in these distinct ways when they cause versus witness any outcome, even when the outcome does not involve harm. Children may, for example, make more active efforts to understand why their toy is in a new location if they did not place it there.

Thus, to draw conclusions about the prosocial functions of guilt specifically, we need to compare cases in which children cause a harmful outcome to cases in which someone else causes a harmful outcome and to cases in which children (vs. someone else) cause a nonharmful outcome. This was the aim of the present study, which examined the development of the prosocial functions of guilt. Our study included 2- and 3-year-old children in keeping with prior work on the development of guilt and sympathy (e.g., Kochanska et al., 1995; Vaish et al., 2009; Zahn-Waxler \& Radke-Yarrow, 1982; Zahn-Waxler et al., 1992). The method was broadly based on the extant developmental work on guilt and sympathy, in which toddlers cause a (contrived) minor mishap (e.g., Kochanska et al., 1995; Zahn-Waxler \& Radke-Yarrow, 1982). Within this situation, we varied two factors in a $2 \times 2$ factorial design: whether the child or another person caused the mishap and whether the mishap harmed someone else or not. As guilt is not expressed by facial or bodily expressions but rather through speech and actions (Keltner \& Buswell, 1996; Zahn-Waxler \& Kochanska, 1990), and as we were chiefly interested in the prosocial functions of guilt, we assessed children's reparative and prosocial behavior, with the aim of examining whether, and at what age, young children demonstrate guilt-motivated reparative and prosocial behavior. Our experimental design permitted us to isolate the effects of guilt from those of sympathy and those of having caused a nonharmful outcome. That is, more reparative and prosocial behavior after children caused harm than after someone else caused harm or after they caused a similar but nonharmful outcome would indicate that guilt distinctly serves to motivate children's reparative and prosocial behavior.

In addition, because in prior work on sympathy in young children (e.g., Vaish et al., 2009), patterns of children's looks have been found to be informative and to effectively distinguish between conditions in which harm versus no harm was caused, we also examined children's looking behavior. Finally, because prior work on guilt indicates that children's responses to specific questions about the mishap are potentially informative and diagnostic about their feelings of guilt (Kochanska et al., 1995, 2002), we also explored children's responses to such questions.

\section{Method \\ Participants}

Participants were 2-year-old children $(N=62,31$ girls) between 21;27 (21 months, 27 days) and 25;29 
$(M=24 ; 1, \quad S D=1 ; 8)$ and 3-year-old children $(N=64,32$ girls $)$ between $33 ; 25$ and $38 ; 4$ $(M=35 ; 18 ; \quad S D=1 ; 6)$. Additional children were tested but excluded due to an unwillingness to participate (four 2-year-olds and five 3-year-olds), experimenter error ( 5 and 3 , respectively), the tower collapsing too early (2 and 3 ), being fussy or distracted (2 and 1), or procedural disruption (6 and 1). Children were recruited from and tested in their daycare centers in a medium-sized German city. All children's parents had given permission for them to participate in child development studies. Parents were not present during testing. Data were collected from June 2011 through May 2012 and from June 2013 through February 2014.

\section{Materials}

The key materials were a block tower that together made a colorful and attractive picture (hereafter called "tower") and two large marble runs (see Figure S1a). Each marble run ended in a "garage" whose door could be opened such that the ball could roll out of it (Figure S1b).

\section{Procedure}

The study had a 2 (outcome: harm, no harm) $\times 2$ (cause: child, E2) between-subjects factorial design. The two experimenters (E1 and E2) first flipped through a picture book with the child (in order to make the child comfortable and encourage the child to talk). Then, in the two harm conditions, E1 "noticed" the tower, excitedly told the child and E2 that it was hers, that the colorful picture had taken her a longtime to finish, and that she was extremely pleased with it. She then said she needed to do some work and that when E2 and the child played they should be careful that her tower does not break or she would be very sad. In the two noharm conditions, E1 "noticed" the tower, shrugged and said she did not know why it was there, and described it neutrally. She then said she needed to work and that when E2 and the child played, the tower might break but that would not matter and it would not bother her. E1 then sat on a chair about $2 \mathrm{~m}$ away, facing away from E2 and the child.

\section{Accident}

After E2 and the child played two unrelated games, E2 brought out the marble runs and she and the child played separately with one each. After the child had played a total of five times, E2 drew the child's attention to a picture behind the child. Although the child was turned away, E2 surreptitiously unblocked the garage of either the child's (child conditions) or her own marble run (E2 conditions). She then drew the child's attention back and both resumed playing. Now either the child's (child conditions) or E2's ball (E2 conditions) rolled into the tower and knocked part of it down. Some part of the tower was left standing for all children, as the full tower was too heavy for the balls to knockdown entirely. In all conditions, E2 stopped playing, looked at the broken tower and said "Oh!" in a mildly surprised (but otherwise neutral) manner. She then alternated gaze neutrally twice between the broken tower and child.

\section{E1's Return}

Approximately $15 \mathrm{~s}$ after the accident, E1 turned around and noticed the broken picture tower and said either "Oh no, my lovely picture" (mildly sadly; harm conditions) or "Oh, the colorful picture" (neutrally; no-harm conditions). E1 then returned, knelt near the broken tower and again said either "My lovely picture" (mildly sadly) or "The colorful picture" (neutrally) while looking at it. Note that the neutral expression was not a flat, expressionless display but rather was intended to convey that E1 was not concerned about the picture tower being broken. E1 then alternated gaze twice between the picture and child (15 s) to give children a chance to respond (e.g., by starting to repair the tower) spontaneously. While E1 then walked over, E2 turned away from the situation and appeared busy.

\section{Questions}

E1 then asked the child four questions: Q1: "What happened?" Q2: "Who did this?" Q3: "Did you do it?" Q4: "What can be done about it?" (cf. Kochanska et al., 1995).

After each question, she waited $5 \mathrm{~s}$ to allow children to respond. During this time, she looked away once to the tower so as to avoid making children feel uncomfortable by fixing her gaze on them for the entire $5 \mathrm{~s}$ as well as to convey to them that her questions referred to the tower. Throughout the questions, E1 was either mildly sad (harm conditions) or neutral (no-harm conditions).

\section{Reassembling}

In all conditions, E1 now moved the broken tower and fallen blocks to one side of the marble 
runs (so they did not block the play area for the marble runs), herself moved to the same side, and neutrally wondered aloud whether the picture could be put together again. She began searching through the fallen blocks and neutrally wondered aloud where certain pieces were (e.g., "Where is the red flower?"). She did this three times over $1 \mathrm{~min}$, and each time she neutrally looked to the child once. If a child gave a block, she accepted it, examined it, and distractedly placed it back down. The picture was thus never actually repaired, which ensured both that the reassembling phase was similar across conditions (rather than having only some conditions result in a rebuilt picture tower) and that children's helping was motivated primarily by a desire to help rather than a desire to see the tower rebuilt.

\section{Stickers}

To explore how general the prosocial functions of guilt might be, we included a final sticker-sharing task that was unrelated to the original transgression. E2 gave E1 and the child each a box with "lots of stickers" (in fact, the child's box had four stickers and E1's had none) and left the room. Once the child opened her box, E1 opened her own and said, "Oh, I don't have any stickers," and looked sadly at her box for $5 \mathrm{~s}$. If the child did not act, E1 said, "Oh, I really want some stickers, but my box is empty," and looked sadly at her box for $5 \mathrm{~s}$. If the child still did not act, E1 looked at the child, said, "Will you give me some?" and alternated gaze twice between the child and her box for $10 \mathrm{~s}$ or until the child shared, whichever happened first. If the child shared at any stage, E1 accepted the sticker(s) and said mildly happily, "Oh, I really like stickers." She then looked at her box (5 s) and then at the box and child twice (10 s). If the child shared again, E1 repeated this behavior. This phase concluded the study.

To end on a positive note, the child was given four stickers and assured that the accident was no one's fault and the tower could easily be fixed.

\section{Coding and Reliability}

As the central goal of this study was to explore the effects of guilt on children's reparative and prosocial behavior, the primary coding focused on these behaviors. This primary coding was conducted by the first author (blind to condition). Table S1 provides details of this coding scheme.

In the E1's return and questions phases (i.e., before E1 began repairing the tower herself), we coded children's "guilt-relevant reparative behavior." Because guilt serves prosocial functions by restoring both physical and social damage, this measure included both physical and verbal reparative behaviors. Regarding physical (nonverbal) reparative behaviors, note that in both the E1's return and questions phases, children had the opportunity to spontaneously attempt to repair the tower by placing fallen blocks onto it. Thus, for each phase, we coded whether children did so. For verbal reparative behaviors, we used transcripts to identify guilt-related speech (apologies, offers to repair, and statements that harm was unintended). As further measures of (more scaffolded) prosocial behavior, we coded how many blocks children gave E1 during reassembling and how many stickers they shared during the stickers phase.

In addition, secondary coding was conducted in order to examine how well children understood the situation and to examine children's more subtle nonverbal responses. There were two aspects to this coding. First, two coders (blind to condition and hypotheses; each coding one age group) used Interact (Mangold International $\mathrm{GmbH}, 2007$ ) to code duration of looks to E1, E2, the broken tower, the garages, and away, and did so during the $15 \mathrm{~s}$ immediately following the accident, during E1's return, and during the questions phase. (Note that looks to the garages and away were not analyzed and are not discussed further. Looks to E1, E2, and the broken tower were analyzed because we felt they best captured our questions of interest: looking to E1 out of guilt or sympathy, looking to E2 if E2 had caused the tower to break, and looking to the broken tower out of concern regarding the mishap.) Second, the first author (blind to condition) coded children's responses to individual questions as follows (adapted from Kochanska et al., 1995) - Q1 ("What happened?"): whether children made statements about the mishap; Q2 and Q3 ("Who did this?" and "Did you do it?"): whether children blamed themselves or accepted responsibility (hereafter "accepted blame"), and whether they blamed someone else or denied responsibility (hereafter "denied blame"); Q4 ("What can be done about it?"): whether children made statements about repair.

Two reliability coders (blind to condition and hypotheses) coded all primary measures and responses to individual questions for $25 \%$ of children $(n=16$ at each age; each coder coded one age group). In addition, two reliability coders (one blind to condition and hypotheses, the other - the first author-blind to condition) coded looking for 
$25 \%$ of children $(n=16$ at each age; each coder coded one age group). Reliability on all measures was excellent, all $\kappa \mathrm{s}>.80$.

\section{Results}

We first present results of the primary measures (reparative and prosocial behaviors) followed by the secondary measures (looking and responses to individual questions during the questions phase).

\section{Guilt-Relevant Reparative Behavior (E1's Return and Questions Phases)}

To quantify guilt-relevant reparative behavior, we gave children a score according to whether or not they produced either physical (nonverbal) or verbal reparative behavior during the E1's return and questions phases (cf. Kochanska et al., 1995). That is, in both the E1's return and the questions phases, children received 1 point if they attempted to repair the tower and 1 point if they expressed guilt in their speech. Each child thus received a score from 0 to 4 .

As a large number of children received scores of 0 on this measure (see Table 1), the data were positively skewed and were thus analyzed using nonparametric tests applying the Monte Carlo permutation method. For each age group, KruskalWallis tests were conducted with the guilt-relevant reparative behavior score as the dependent variable and condition as the independent variable. Among 3-year-olds, this analysis indicated a significant effect of condition, $H(3)=14.13, p=.002$. Pairwise comparisons using Mann-Whitney $U$ tests indicated that children in the child-harm condition scored significantly higher $(M=1.13, S D=1.36)$ than children in all other conditions (all $p s<.043$; see

Table 1

Number of Children by Age and Condition Who Received Each Score for Guilt-Relevant Reparative Behavior (E1's Return and Questions Phases Combined)

\begin{tabular}{|c|c|c|c|c|c|c|c|c|c|c|}
\hline \multirow[b]{3}{*}{ Condition } & \multicolumn{5}{|c|}{ 3-year-olds } & \multicolumn{5}{|c|}{ 2-year-olds } \\
\hline & \multicolumn{10}{|c|}{ Score } \\
\hline & 0 & 1 & 2 & 3 & 4 & 0 & 1 & 2 & 3 & 4 \\
\hline Child-Harm & 8 & 2 & 3 & 2 & 1 & 13 & 1 & 2 & 0 & 0 \\
\hline Child-No harm & 13 & 2 & 1 & 0 & 0 & 11 & 5 & 0 & 0 & 0 \\
\hline E2-Harm & 15 & 1 & 0 & 0 & 0 & 14 & 0 & 1 & 0 & 0 \\
\hline E2-No harm & 15 & 1 & 0 & 0 & 0 & 14 & 1 & 0 & 0 & 0 \\
\hline
\end{tabular}

Figure 1). None of the other conditions differed significantly from one another, all $p s>.475$. Among 2-year-olds, in contrast, the Kruskal-Wallis test did not reveal a significant effect of condition, $p=.264$. These analyses thus indicated a specific effect of guilt on the guilt-relevant reparative behavior of 3 -year-old children but failed to find a significant effect on the reparative behavior of 2-year-old children.

Note that our measure of guilt-relevant reparative behavior consisted of both verbal and nonverbal behaviors. However, as 2-year-olds possess limited verbal abilities, it is possible that 2-year-olds did evince guilt through nonverbal reparative behaviors, but that by pooling verbal and nonverbal behaviors into one score, we overlooked guilt-specific effects among these younger children. We thus conducted separate analyses of verbal versus nonverbal guiltrelevant reparative behavior. The results paralleled those from the analyses of combined scores: Among 3-year-olds, there was a significant condition difference in both verbal and nonverbal reparative behaviors, whereas among 2-year-olds, there was no significant condition difference in either category (see Appendix S1, for details of these analyses). Nonetheless, the descriptive data (provided in Table S3) indicated that 2-year-olds displayed almost exclusively nonverbal reparative behaviors, with only one child at this age showing any verbal reparation, suggesting that among such young children, nonverbal behaviors may indeed provide more sensitive measures of emotional and motivational processes than verbal behaviors.

\section{Reassembling}

A 2 (age: 2, 3 years) $\times 2$ (outcome: harm, no harm) $\times 2$ (cause: child, other) analysis of variance (ANOVA) with number of blocks given as the dependent measure revealed only a significant main effect of outcome, $F(1,118)=5.295, p=.023$, $\eta_{\mathrm{p}}^{2}=.043$. Children in the harm conditions gave E1 significantly more blocks $(M=1.18, S D=2.02)$ than children in the no-harm conditions $(M=0.49$, $S D=1.08)$, thus revealing an overall effect of sympathy at both ages (see Figure 2). The number of blocks given in each condition at each age is provided in Table S4.

\section{Stickers}

We first considered how many stickers children shared. A 2 (age) $\times 2$ (outcome) $\times 2$ (cause) ANOVA revealed only a significant main effect of 


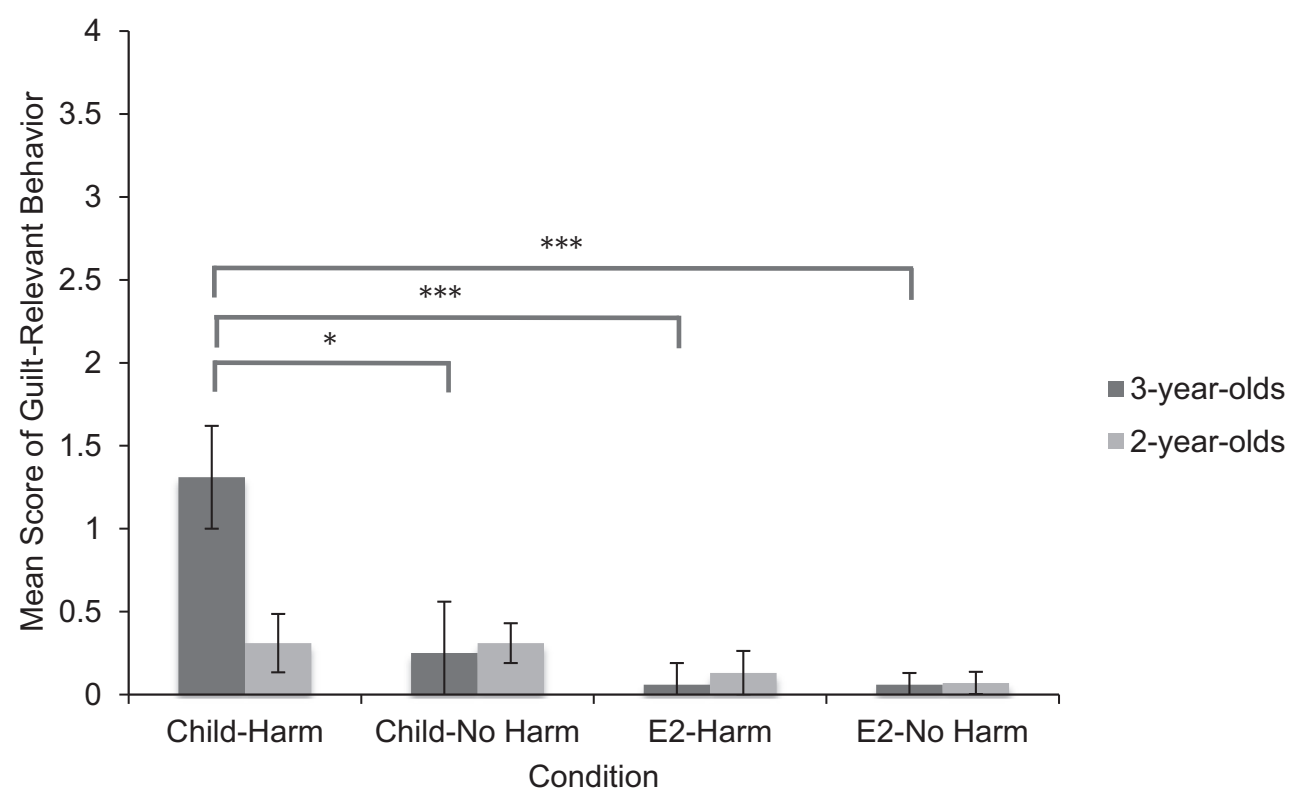

Figure 1. Mean reparative behavior scores (and standard errors) in each condition and at each age. ${ }^{*} p<.05 . * * * p<.005$.

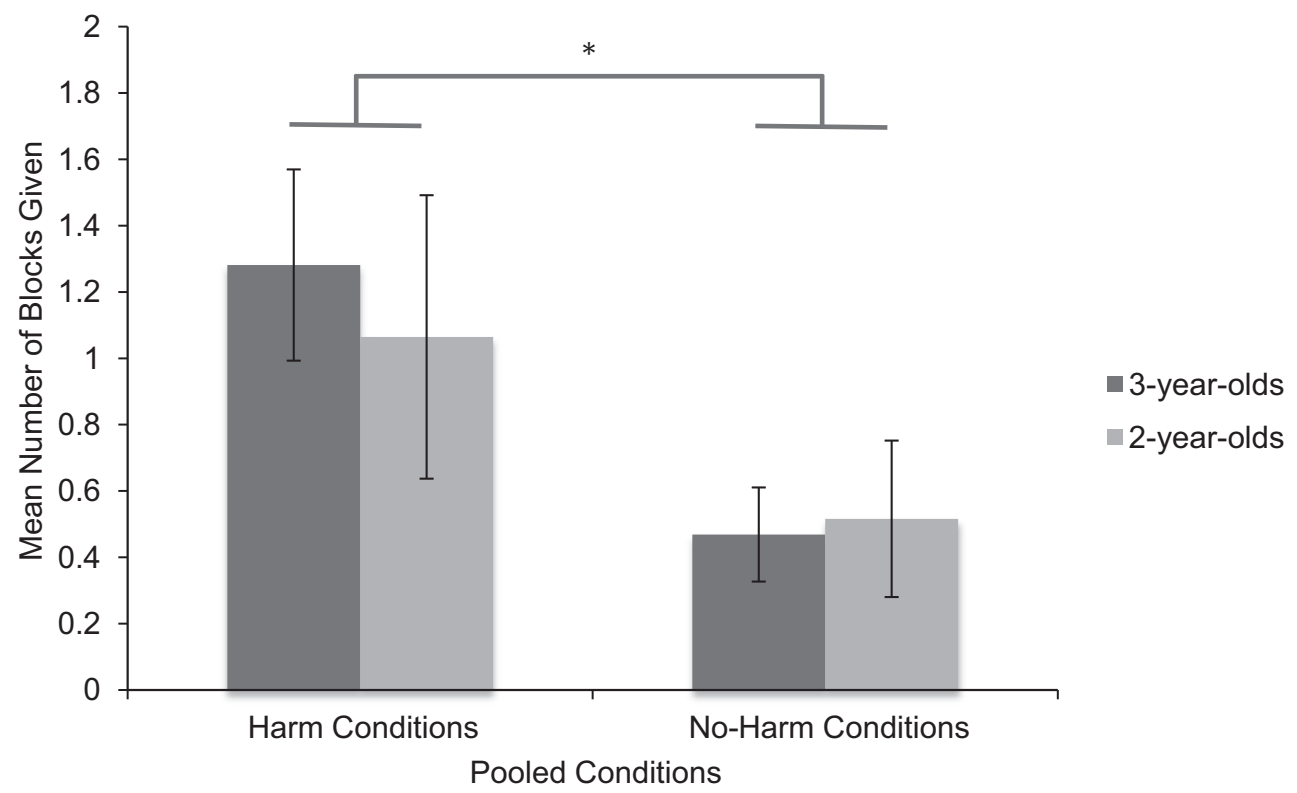

Figure 2. Mean number of blocks given to E1 in the reassembling phase in the two harm conditions (child-harm and E2-harm) versus the two no-harm conditions (child-no harm and E2-no harm) at each age. ${ }^{*} p<.05$.

age, $F(1,118)=12.97, p<.0005, \eta_{\mathrm{p}}^{2}=.099:$ Threeyear-olds shared more stickers $(M=1.16$, $S D=0.80)$ than 2-year-olds $(M=0.58, S D=0.95)$.

We thus considered the age groups separately in a second analysis, in which we were interested in whether children were willing to give up half (i.e., 2) or more of their stickers versus less than half of their stickers. Among 3-year-olds, a 2 (outcome) $\times$ 2 (cause) logistic regression revealed only a significant main effect of outcome, $z=2.14$, $p=.033$. Children at this age were more likely to share half or more of their stickers if E1 had previously been harmed than not harmed, again indicating an effect of sympathy. Among 2-year-olds, a similar analysis revealed no significant effects (see Table S5). Details of these logistic regressions, and further analyses of children's sharing behavior, are provided in Appendix S1. 
In addition to children's reparative and prosocial behaviors, we examined the secondary measures of looking and responses to individual questions during the questions phase. Here, we will briefly summarize the results of these analyses; details are in Appendix S1.

\section{Looking}

We analyzed the mean percentage of time children spent looking to E1, E2, and the tower during the $15 \mathrm{~s}$ immediately following the accident (during which all conditions were identical) as well as during E1's return and the questions phase.

\section{5 s Following Accident}

In the $15 \mathrm{~s}$ immediately following the accident, 2-year-olds did not look differentially to E1 across conditions (all $p s>.161$ ), but they looked for a significantly greater proportion of time to E2 when E2 had caused the accident (i.e., in the E2 conditions) than if they had caused it (child conditions), and conversely, they looked for a significantly greater proportion of time to the broken tower in the child than in the E2 conditions (both $p s<.042$ ). Among 3-year-olds, looking to E1, E2, and the tower all revealed significant Cause $\times$ Outcome interactions (all ps <.043; for looks to E2 only, this interaction emerged for boys but not girls), indicating that both factors impacted the looking patterns in this older group. Thus, immediately after the accident (when all conditions were identical), 2-year-olds tracked the cause of the accident but perhaps did not track whether or not the outcome was harmful, whereas 3-year-olds tracked both cause and outcome.

\section{E1's Return and Questions Phases}

Once E1 returned (and displayed sadness in the two harm conditions), children at both ages showed evidence of tracking both cause and outcome. Specifically, across ages, children looked more to E1 in the harm conditions than the no-harm conditions $(p<.0005)$. Moreover, among 3-year-olds, looking to E2 revealed a significant Cause $\times$ Outcome interaction $(p=.003)$. This interaction was driven by a significantly greater proportion of time spent looking to E2 in E2-harm than in any other condition (all ps < .007), suggesting that 3-year-olds may have expected E2 to respond in some way, such as by accepting responsibility or repairing the damage she had caused.

Analyses of looks to the broken tower revealed that again 2-year-olds looked more to the tower in the child than the E2 conditions $(p<.0005)$. Furthermore, across ages, looking to the tower revealed a significant Cause $\times$ Outcome interaction $(p=$ .048), driven by significantly less looking to the tower in E2-no harm than in any other conditions (all $p s<.006)$. Thus, once E1 returned to the scene and was sad if harmed or neutral if not harmed, both 2- and 3-year-olds demonstrated sensitivity to both of the factors crucial for guilt, namely, cause and outcome. On the whole, though children's looking behavior did not reveal a guilt-specific effect at either age, it did suggest that children at both ages distinguished whether they versus E2 had caused the mishap and also distinguished whether or not the mishap caused harm to E1.

\section{Individual Questions}

Analyses of children's responses during the questions phase only included children who provided some verbal response on the particular question(s) being analyzed. Children's responses to individual questions were analyzed using 2 (age) $\times 2$ (outcome) $\times 2$ (cause) logistic regressions. The strategy for these analyses was as follows: We first compared the full model to a null model including only the intercept. If the full model predicted the data significantly better than the null model, the full model was compared to a reduced model without the three-way interaction. If the full model predicted the data better than this reduced model, then the three-way interaction was retained. If not, the three-way interaction was removed, and we proceeded to test whether each two-way interaction and then (if needed) whether each main effect contributed significantly to the model. For the analyses below, we present only the final models obtained with this strategy. Detailed descriptive data are provided in Table S5.

\section{Q1: What Happened?}

For Q1, we compared the proportion of children who made statements about the mishap. The final model only included age as a factor and revealed a significant effect of age $(z=4.32, p<.0005)$, such that 3-year-olds were more likely to respond with statements about the mishap than were 2-year-olds.

\section{Q2 (Who Did It?) and Q3 (Did You Do It?) Combined}

Accept blame. For this analysis, we pooled Questions 2 and 3 and assigned children a score of 1 if they accepted blame and 0 if they did not. The final model consisted of the three main effects and the 
Age $\times$ Outcome and Age $\times$ Cause interactions This model revealed an Age $\times$ Cause interaction $(z=3.13, p=.002)$. Three-year-old children were more likely to accept blame when they had caused the accident than when E2 had caused it $(z=3.24$, $p=.001$ ), whereas there was no effect of cause among 2-year-olds. Furthermore, the logistic regression also revealed an Age $\times$ Outcome interaction $(z=3.10, p=.002)$. Interestingly, the factor "outcome" $^{\prime \prime}$ showed opposite effects at the two ages: Whereas 3-year-olds were more likely to accept blame when no harm had been caused $(z=2.01$, $p=.044)$, 2-year-olds were more likely to do so when harm had been caused $(z=2.37, p=.018)$.

Deny blame. We pooled Questions 2 and 3 and assigned children a score of 1 if they denied blame and 0 if they did not. The final model consisted of the three main effects and the Age $\times$ Outcome interaction. This model revealed a marginal Age $\times$ Outcome interaction, $z=1.87, p=.06$. Considering each age separately revealed that 3-yearolds denied blame more when harm was caused than when no harm was caused ( $z=2.96, p=.003)$. No such difference emerged among 2-year-olds. The logistic regression also revealed main effects of age $(z=3.93, p<.0005)$ and cause $(z=2.81$, $p=.005)$. Three-year-olds were more likely to deny blame than 2-year-olds, and across ages, children denied blame more when E2 had caused the accident than if they had caused it (though these responses were very infrequent among 2-year-olds, indicating that the effect was primarily driven by the 3-year-olds; see Table S5). Together, the results of children's acceptance and denial of responsibility, in conjunction with their looking behavior, suggest that children at both ages kept track of who caused the accident and whether or not harm was caused.

\section{Q4: What Can Be Done About It?}

For Q4, we compared the proportion of children who made statements about repair. A 2 (age) $\times 2$ (outcome) $\times 2$ (cause) logistic regression revealed only a main effect of age, $z=2.60, p=.009$ : Threeyear-olds responded with statements about repair more than 2-year-olds.

\section{Discussion}

In this study, we examined the development of the prosocial functions of guilt. Two- and 3-year-old children either accidentally caused a mishap or witnessed someone else causing the same mishap, and the mishap either harmed another person or did not harm anyone. Three-year-olds showed the greatest prosocial, reparative behavior-as seen in their attempts to mend the physical damage or verbally express guilt - when they caused a harmful mishap, whereas 2-year-olds did not show a guiltspecific effect. Guilt thus promotes prosocial behavior by at least 3 years of age.

Interestingly, even at age 3, the effect of guilt was only evident relatively soon after the mishap -when the victim first returned and as she was asking children questions. Once the victim began searching for blocks to repair the picture tower (reassembling), children's prosocial behavior showed a more general effect of sympathy, as children helped the victim more if she had been harmed, regardless of the cause. This effect of sympathy persisted on the final (unrelated) sticker-sharing task (though note that the proportion of 3-yearolds who shared half or more stickers in childharm was more than double that in any other condition; this hints that guilt may have continued to weakly_though nonsignificantly-impact children's prosocial behavior). A possible reason for this change from guilt to sympathy is that children assuaged their guilt early on and so their subsequent reparative and prosocial behavior may no longer (or only weakly) have been motivated by guilt, whereas their sympathy for the victim persisted. This makes sense given that guilt is experienced as an aversive emotion that one is highly motivated to expiate (Nelissen \& Zeelenberg, 2009; Regan et al., 1972), whereas sympathy may not be experienced as aversive to the same degree.

Prior work has suggested that children show guilt-relevant behaviors as early as 2 years of age (Barrett et al., 1993; Zahn-Waxler \& Kochanska, 1990; Zahn-Waxler \& Radke-Yarrow, 1982). However, that work did not tease apart guilt and sympathy or guilt and the awareness of having caused an outcome (Hoffman, 1976, 1982). Our design enabled us to do so and revealed that it may only be by age 3 rather than 2 that guilt motivates prosocial behavior. It is unclear, however, why the effect was not evident in the current study at age 2. Note that these younger children did show evidence of tracking the two components of guilt separately: They kept track of cause, as they showed significantly different looking patterns if they versus someone else had caused the accident, and they kept track of outcome, as they showed greater prosocial behavior (reassembling phase), looked more to the victim, and accepted blame more (Q2 and Q3) when the victim had been harmed. 
Interestingly, although 2-year-olds tracked cause immediately after the accident (when conditions were identical), they seemed to track outcome only once E1 returned to the scene (and expressed sadness if harmed). This suggests that their understanding of the situation was not as robust as that of 3-year-olds, whose looking behavior indicated that they tracked both cause and outcome right away. Nonetheless, once E1 returned and provided additional cues, the 2-year-olds did attend to both cause and outcome. Thus, the absence of a guiltspecific prosocial effect in 2-year-olds may not result from the absence of one or both components of guilt; rather, either the components do not yet interact to give rise to guilt, or they do give rise to guilt but children of this age have not yet learned to alleviate their guilt through reparative acts. Still, even 2-year-olds may show guilt-specific prosocial behaviors in other (simpler) situations or in interactions with familiar others (cf. Zahn-Waxler et al., 1992). This is a promising avenue for future research.

Critically, 2-year-old children did show an effect of sympathy on prosocial behavior during the reassembling phase. This replicates prior findings that, by age 2, children are concerned for and prosocial toward those in need (e.g., Hepach et al., 2012a; Vaish et al., 2009; Zahn-Waxler et al., 1992). One may ask why this effect of sympathy first emerged during reassembling and not soon after the mishap. One possibility is that soon after the mishap, when the victim was sad but not trying to achieve a particular goal, children sympathized with her but did not know how to help. During reassembling, however, the victim demonstrated a concrete need (searching for blocks), which clarified to children how they could act on their sympathy and help the victim. This fits with findings that during the 2nd year, children's prosocial behavior occurs primarily in goal-oriented helping situations and relies heavily on clear communication about the person's needs (Svetlova, Nichols, \& Brownell, 2011). Indeed, 2-year-olds in the child-harm condition may even have experienced guilt soon after the mishap, but in the absence of the victim demonstrating a concrete need, they did not know how to repair; then, by the reassembling phase, their guilt may have weakened and they may have experienced primarily sympathy, and with the scaffolding from the victim, they were now able to act on that sympathy. The lack of scaffolding soon after the mishap may thus have masked an effect of guilt at 2 years, a possibility that must be considered in future work on guilt in such young children.
Children's responses to the questions provided further insights. First, though children at both ages tracked both cause and outcome, they did not accept or deny blame as a specific function of guilt (Q2 and Q3). In prior work, accepting (and not denying) blame has been thought to reflect guilt (e.g., Kochanska et al., 1995), but our findings hint that these measures may instead track cause and outcome separately. Moreover, children's statements about the mishap and repair $(\mathrm{Q} 1$ and Q4, respectively) did not differ across conditions, suggesting that children may respond with such statements whenever a mishap occurs, regardless of cause or outcome. Thus, young children's verbal responses related to the mishap, blame, and repair -all of which seem pertinent to guilt-may not exclusively reflect guilt.

It was also interesting that 2-year-olds accepted more blame when harm was caused, regardless of who caused it (Q2 and Q3). These findings are consistent with the proposal that toddlers often become confused about the cause of others' distress and even feel causally implicated in that distress regardless of culpability (Zahn-Waxler \& Kochanska, 1990; Zahn-Waxler, Radke-Yarrow, \& King, 1979). This raises the possibility that even as observers, 2-year-olds feel responsible for others' distress and thus experience guilt rather than sympathy. On this account, development may not involve the differentiating out of a general sympathy response into guilt and sympathy, but rather the differentiating out of a general guilt response. This is a fascinating possibility to explore in future work.

In conclusion, our findings show that from early in development, guilt begins to motivate reparative behavior. By at least 3 years of age, children make amends for their transgressions by attempting to repair and verbally expressing guilt. Such prosocial acts likely appease victims and observers, and thereby repair damaged relationships. Guilt thus serves vital prosocial functions from early in ontogeny.

\section{References}

Barrett, K. C., Zahn-Waxler, C., \& Cole, P. M. (1993). Avoiders vs. amenders: Implications for the investigation of guilt and shame during toddlerhood? Cognition and Emotion, 7, 481-505. doi:10.1080/0269993930840 9201

Baumeister, R. F., Stillwell, A. M., \& Heatherton, T. F. (1994). Guilt: An interpersonal approach. Psychological Bulletin, 115, 243-267. doi:10.1037/0033-2909.115.2.243 
Fessler, D. M. T., \& Haley, K. J. (2003). The strategy of affect: Emotions in human cooperation. In P. Hammerstein (Ed.), Genetic and cultural evolution of cooperation (pp. 7-36). Cambridge, MA: MIT Press.

Frank, R. H. (1988). Passions with reason: The strategic role of the emotions. New York, NY: W. W. Norton \& Company.

Hepach, R., Vaish, A., \& Tomasello, M. (2012a). Young children are intrinsically motivated to see others helped. Psychological Science, 23, 967-972. doi:10.1177/ 0956797612440571

Hepach, R., Vaish, A., \& Tomasello, M. (2012b). Young children sympathize less in response to unjustified emotional distress. Developmental Psychology, 49, 11321138. doi:10.1037/a00295

Hoffman, M. L. (1976). Empathy, role taking, guilt, and development of altruistic motives. In T. Lickona (Ed.), Moral development and behavior (pp. 124-143). New York, NY: Holt, Rinehart, \& Winston.

Hoffman, M. L. (1982). Development of prosocial motivation: Empathy and guilt. In N. Eisenberg (Ed.), The development of prosocial behavior (pp. 281-338). New York, NY: Academic Press.

Keltner, D. (1995). Signs of appeasement: Evidence for the distinct displays of embarrassment, amusement, and shame. Journal of Personality and Social Psychology, 68, 441-454. doi:10.1037/0022-3514.68.3.441

Keltner, D., \& Anderson, C. (2000). Saving face for Darwin: The functions and uses of embarrassment. Current Directions in Psychological Science, 9, 187-192. doi:10.1111/1467-8721.00091

Keltner, D., \& Buswell, B. N. (1996). Evidence for the distinctness of embarrassment, shame, and guilt: A study of recalled antecedents and facial expressions of emotion. Cognition and Emotion, 10, 155-171. doi:10.1080/ 026999396380312

Ketelaar, T., \& Au, W. T. (2003). The effects of feelings of guilt on the behaviour of uncooperative individuals in repeated social bargaining games: An affect-as-information interpretation of the role of emotion in social interaction. Cognition and Emotion, 17, 429-453. doi:10.1080/ 02699930143000662

Kochanska, G. (1991). Socialization and temperament in the development of guilt and conscience. Child Development, 62, 1379-1392. doi:10.1111/j.1467-8624.1991. tb01612.x

Kochanska, G., Casey, R. J., \& Fukumoto, A. (1995). Toddlers' sensitivity to standard violations. Child Development, 66, 643-656. doi:10.1111/j.1467-8624.1995.tb00895.x

Kochanska, G., Gross, J. N., Lin, M.-H., \& Nichols, K. E. (2002). Guilt in young children: Development, determinants, and relations with a broader system of standards. Child Development, 73, 461-482. doi:10.2307/ 1130813

Mangold International GmbH. (2007). Interact (Version 8.0) [Computer software]. Arnstorf: Germany: Author.

Nelissen, R. M. A., \& Zeelenberg, M. (2009). When guilt evokes self-punishment: Evidence for the existence of a Dobby effect. Emotion, 9, 118-122. doi:10.1037/a0014540
Regan, D. T., Williams, M., \& Sparling, S. (1972). Voluntary expiation of guilt: A field experiment. Journal of Personality and Social Psychology, 24, 42-45. doi:10.1037/ h0033553

Smith, C. E., Chen, D., \& Harris, P. L. (2010). When the happy victimizer says sorry: Children's understanding of apology and emotion. British Journal of Developmental Psychology, 28, 727-746. doi:10.1348/026151009X475343

Smith, C. E., \& Harris, P. L. (2012). He didn't want me to feel sad: Children's reactions to disappointment and apology. Social Development, 21, 215-228. doi:10.1111/ j.1467-9507.2011.00606.x

Svetlova, M., Nichols, S. R., \& Brownell, C. A. (2011). Toddlers' prosocial behavior: From instrumental to empathic to altruistic helping. Child Development, 81, 1814-1827. doi:10.1111/j.1467-8624.2010.01512.x

Tangney, J. P., \& Dearing, R. (2002). Shame and guilt. New York, NY: Guilford.

Vaish, A., Carpenter, M., \& Tomasello, M. (2009). Sympathy through affective perspective-taking and its relation to prosocial behavior in toddlers. Developmental Psychology, 45, 534-543. doi:10.1037/a0014322

Vaish, A., Carpenter, M., \& Tomasello, M. (2011). Young children's responses to guilt displays. Developmental Psychology, 47, 1248-1262. doi:10.1037/a0024462

Wellman, H. M., Larkey, C., \& Somerville, S. C. (1979). The early development of moral criteria. Child Development, 50, 869-873. doi:10.2307/1128956

Zahn-Waxler, C., \& Kochanska, G. (1990). The origins of guilt. In R. A. Thompson (Ed.), The Nebraska Symposium on Motivation 1988: Socioemotional development (Vol. 36, pp. 183-258). Lincoln, NE: University of Nebraska Press.

Zahn-Waxler, C., Kochanska, G., Krupnick, J., \& McKnew, D. (1990). Patterns of guilt in children of depressed and well mothers. Developmental Psychobiology, 26, 51-59. doi:10.1037/0012-1649.26.1.51

Zahn-Waxler, C., \& Radke-Yarrow, M. (1982). The development of altruism: Alternative research strategies. In N. Eisenberg (Ed.), The development of prosocial behavior (pp. 109-137). New York, NY: Academic Press.

Zahn-Waxler, C., Radke-Yarrow, M., \& King, R. A. (1979). Child rearing and children's prosocial initiations toward victims of distress. Child Development, 50, 319330. doi:10.2307/1129406

Zahn-Waxler, C., Radke-Yarrow, M., Wagner, E., \& Chapman, M. (1992). Development of concern for others. Developmental Psychology, 28, 126-136. doi:10.1037// 0012-1649.36.5.531

\section{Supporting Information}

Additional supporting information may be found in the online version of this article at the publisher's website:

Figure S1. Set Up of Picture Tower and Marble Runs (a), and a Ball Rolling Through the Open Garage of One Marble Run (b). 
Table S1. Coding Scheme.

Table S2. Number of Children by Age and Condition Who Received Each Score for Guilt-Relevant Reparative Behavior (15 s Following Accident).

Table S3. Number of Children by Age and Condition Who Received Each Guilt-Relevant Reparative Behavior Score in the Nonverbal ("Attempts to Repair") and Verbal ("Guilt in Speech") Categories (E1's Return and Questions Phases Combined).
Table S4. Mean Number (and Standard Deviation) of Blocks Children Gave to E1 in the Reassembling Phase.

Table S5. Percentage of Children Who Provided Each Type of Response (Questions Phase) and Shared Half or More Stickers (Stickers Phase).

Appendix S1. Detailed Results. 